\title{
Needs Analysis of Contextual Training for Automotive Technicians
}

\section{Eka Andriyani1 ${ }^{*}$, R.A Murti Kusuma Wirasti2 ${ }^{2}$ Suyitno Muslim³}

1,2,3 Postgraduate Educational Technology, State University of Jakarta, East Jakarta, Indonesia

A R T I C L E I N F O

Article history:

Received 10 October

2020

Received in revised

Form 15 October 2020

Accepted 30 October

2020

Available online 01

November 2020

Keywords:

Needs Analysis, Training,

Automotive Technicans.

\begin{abstract}
A B S T R A C T
The advancement of technology make automotive industry has to improve rapidly, it causes the training for technicians must be update continuously, so it confuses some instructors it caused some of these trainings often ineffective, they are not what the company truly needs. This study aims to analyze the needs to make an effective training in the automotive industry. This method was developed to minimize errors that would occur while develop a training for technicians. This study used a qualitative approach, the data to be studied were collected through interviews with technicians and instructors, literature review also used in this study. The results of this study is to produce a needs analysis method that considers aspects of learning according to context in order to keep up with technology advancement. A training can be effective if the needs of the company were fulfilled, utilizing learning facilities that company already has can also increase the training development process. The contribution of the results of this research to the field of educational technology is a method for analyzing training needs specifically for technicians in order to assist other researchers in field of educational technology to develop training for technicians.
\end{abstract}

\section{Introduction}

Companies engaged in the automotive sector are growing rapidly in line with technological developments and times, therefore, the development of automotive products such as cars will continue to grow (Adam \& Foster, 2000; Gonzalez \& Martins, 2016). This requires technicians to have the knowledge, skills and attitudes to suit these developments and it often confuse some instructors when they have to create a new training so sometimes they decide to not create the new one and keep using the old training programs. It means some training materials are not relevant to new knowledge, skills and attitudes required in technician's job (Adam \& Foster, 2000; Yahaya, 2018).

Some new training program is needed to keep up with technological developments. There are many ineffective trainings for technicians in the automotive sector because some customers still complain such as: the repair service is long; the technicians are less competent and some even complain that they don't get the best service the company has promised. This could be bad if the company just leave it as it is now, their reputation will decline (Bucklin et al., 2018; Gonzalez \& Martins, 2016). Generally, training in automotive companies is needed only when they have new products. The training itself has several types that have certain characteristics, these types must be adapted to the type of material to be studied and the situation and conditions of the company (Gonzalez \& Martins, 2016).

Safety of automotive product is important because it affects the safety of its users as well so every technician is required to have high competence in maintaining and repairing automotive products so that in automotive companies, mastery of technician competence will certainly affect customer satisfaction related to company quality (LeBrasseur \& Nasierowski, 1991; Petruni et al., 2019). This causes the need for training in automotive companies, whether it is updating existing training or designing new training.

The development (development) of a training is never separated from the research process (research) first. Why is this research process important? Because this research process contains a needs analysis, this analysis is related to what kind of training will be developed next (Chyung, 2008). There are several types of needs analysis, even some theories also discuss not only instructional needs but also the need to solve non-instructional employee performance problems (Prawiradilaga \& Chaeruman, 2018). 
Basically, the concept of needs originates from a shortage. This deficiency will create a gap between the expected results and the current results. Needs and wants/ideals are 2 different but also related concepts. It is not uncommon for these two concepts to mix so that making a decision in choosing a problem solution jumps directly to designing something you want (Suparman, 2014). For example, a training that was designed because of orders from superiors or an institution even though the training to be designed was not a priority. This priority needs to be resolved is also a problem in research.

How to analyze the instructional needs of the growing automotive company in Indonesia? This is what will be discussed in this article because the characteristics of a fast growing automotive require specific methods of analysis. Until this point has explained the concept of training, types of training delivery and needs, it is time to discuss instructional development because needs analysis is one of the stages in development so understanding the concept of development is important.

Development is one of the important educational technology areas. This is because educational technology adapts a concept that uses a systems approach (Brown \& Green, 2018; Bucklin et al., 2018; Seels \& Richey, 1994). From the theories that have been described it can be concluded that the research stage is very important because it determines the final result of what will be developed. Research is also carried out to analyze the need for proper training.

There are several development models that can be used as a reference in making training. Dick \& Carey, MPI and Borg \& Gall are 3 examples of development models that can also be methods of developing instructional systems (Brown \& Green, 2018). These development models are models that are used as a reference for making training programs in general, therefore the needs analysis of these models does not explain further for application in specific fields.

The following are some examples of research that has been carried out in the automotive or engineering sector such as in Bucklin's research, the results of this study state that to balance the development of the automotive industry and the tight budgets in today's companies, context-based learning is a good solution (Bucklin et al., 2018). Combined with the results of study suggest that adult education should be encouraged to see events that occur in a larger context for program development so that context-based training is also better applied in learning for adult technicians (Shi, 2017).

In previous research, blended-learning was used in learning in the automotive industry for procedural materials. This study develops a learning system by sorting the type of material to be taught face-to-face and the material to be studied independently (Hrastinski, 2019; Moica et al., 2019). As a result, this training proved to be more effective than full face-to-face with the classical method. The success of this training is supported by the results of research where this study explains that blended learning can have many definitions but mostly refers to a combination of some material that is done faceto-face and some online (Hrastinski, 2019).

The results of study explain that the challenges that must be faced in designing training for technicians when using e-learning in engineering, especially because $e$-learning must be able to replace all learning that is done face-to-face (Yahaya, 2018). Another research has similarities to the type of material, namely diagnosing damage but it must be considered about the budget to develop it considering the speed of changes in automotive products (Ferreira et al., 2018; Thomsen et al., 2017).

Some of the research results described earlier are examples of training developed through a needs analysis process in advance so that they can answer the company's needs well, if there are deficiencies in the training, these deficiencies can be reviewed and looked for where the wrong steps were then corrected. Each training developed in previous studies has specifications that are only suitable for addressing the problems under study. It is this specification that needs to be sought with a need's analysis.

Combining the important aspects of developing training for technicians from theories and journals, will lead researchers to formulate a specific needs analysis method to develop job-context training for technicians in the automotive field. This study aims to find a new method in analyzing the training needs for technicians.

\section{Methods}

This research was conducted using a qualitative approach in which the researcher will study instructional development research in the automotive sector as well as assess the needs analysis of several instructional development models and journals to obtain specific requirements analysis methods required by training for technicians.

The criteria for the journals to be studied are have a reference for the development model used, have clear research methods, produce products that are right on target. These journals are samples that represent training development research in the automotive sector in 2016-2020. the studies studied will focus on those carried out in Indonesia so that the conditions of the company are appropriate. 
Interviews were also conducted with technicians and instructors at several training centers owned by several automotive companies in Indonesia as a source of data to strengthen the results of the study. After all data from studies, observations and interviews have been collected, these data will be analyzed.

The activities that will be carried out in this research are assessing aspects of a good training development needs analysis from development model theories. The steps that will be taken at this stage are looking for theories about the development model that can be a research method as well because it uses the research (research) process before development, looking for the same important aspects of needs analysis, recording the results of theoretical studies.

Collecting research journals that discuss instructional development for technicians. The steps taken at this stage are searching for journals primarily about companies in Indonesia) with appropriate keywords (e.g.: training, automotive, technician) and keeping journals in accordance with keywords. Separating research that uses a needs analysis process and those that do not. The steps taken at this stage are creating a table for research that goes through the need's analysis process first or not, removing research that cannot be detected from the need's analysis from the table.

Assessing any aspects of the research needs analysis that lead to these instructional products. The steps taken at this stage are creating a column 'important aspects of the needs analysis', assessing which aspects of the needs analysis are considered in these studies, documentation of the results of the study. Creating interview guides for technicians and instructors. The questions that will be asked of the instructor, are the aspects of the needs analysis from the journal review correct? In your opinion, is this aspect necessary to be one of the aspects that are considered in the need's analysis?

Conducting interviews, the steps taken at this stage are determining the instructor to be interviewed, making an appointment with the technician and instructor, carrying out the interview according to the promised time and place and asking questions according to the guidelines, and document the results of the interview. Analyzing interview results. The steps taken at this stage are processing the interview data into diagrams, documentation of the results of data processing. Conclude the research results, such as combining important aspects of theory and journal studies, and writing research results in the form of a method for analyzing needs.

\section{Result and Discussion}

\section{Result}

The stages of the instructional needs analysis for technicians are formulated by identifying instructional needs and writing general instructional goals, identifying the behavior and initial characteristics of the technician, and analyzing instructional and technology. Identifying the needs and formulation of TIU are closely related because only problems related to the lack of knowledge, skills and attitudes can produce TIU formulations. Information about the needs to be analyzed was obtained from 3 groups, namely students (Technicians), service users (Head of workshops), educators (Instructors). Technicians have initial characteristics and behaviors in the form of knowledge, skills and initial attitudes before training begins, characteristics and initial behaviors that affect the ongoing training process that must be analyzed, among others educational background and previous experience that builds the competencies they currently acquire. This needs to be known in advance to prevent the material that will be learned from being repeated in the new training with the training they have undergone before. Motivation to learn that builds their motivation to learn. This is important to analyze because the motivation of adults to learn is strongly influenced by internal motivation. Access to learning resources relevant to the training material. Ability here means whether they have hardware such as gadgets and laptops to access the internet or materials that will be provided by the training provider.

Instructional analysis is the stage where determining the material and materials to be discussed in the training, combined with the analysis of learning materials, available facilities and infrastructure, makes it easier to formulate learning strategies at the time of design. Instructional analysis process determine the material needed by the technician to achieve results according to instructional objectives. Each learning goal must have small goals that can help to achieve the final goal, determine some materials that can guide the technician to understand the instructional objectives. Define a sequence of small predefined goals, determine its competency structure. Can be arranged hierarchically, procedurally, cluster or mixed. Analyze learning materials, facilities and infrastructure that are already available and determine what tools and materials can support the materials. These stages are described above. 


\section{Discussion \\ Identify instructional needs and write down general instructional goals}

Identifying the needs and formulation of TIU are closely related because only problems related to the lack of knowledge, skills and attitudes can produce TIU formulations. Information about the needs to be analyzed was obtained from 3 groups, namely students (Technicians), service users (Head of workshops), educators (Instructors) (Deveci, 2017; Henshall et al., 2017).

The information that is sought in identifying instructional needs is the competency of the technician currently possessed and compared with the competencies that should be possessed. The process of identifying needs can be seen in the following step 1, identify the gaps between the current and the supposed to be achieved in training performance/outcomes. Step 2, assessing the significance of the effect of the gap on the institution. By conducting this assessment, it will be known whether this gap will be a priority or not. Some of the things that will be analyzed in this step are the impact of the problem if it is not resolved as soon as possible, the extent of the problem solving scope, the relationship between problem resolution and institutional progress. Step 3, look for the causes of gaps. By analyzing the causes of gaps, it will be known whether the gaps occur due to a lack of knowledge, skills and attitudes of technicians or not. In this step, activities are carried out such as analyzing possible causes of gaps, dividing gaps caused by a lack of knowledge, skills and attitudes with those who are not, classifying the causes of gaps caused by a lack of knowledge, skills and attitudes.

Step 4, conduct an interview with a technician. If the results of the interview show that the technicians have received prior knowledge / training, then the gap will go directly to step 5 . If the results of the interview show that they have never received any education / training before then proceed to step 8. Step 5, further interviews with the technician. If the results of the interview show that technicians receive frequent education / training, then they will proceed to step 6. If the results of the interview show that they rarely receive education / training, then go to step 7. Step 6, the problem can be resolved by asking a technician to perform non-standard tasks (e.g. maintaining / repairing a component in an automotive product). After practicing it, the technician will be given feedback to fix the shortcomings.

Step 7, technicians should be given the opportunity to practice more to enrich their knowledge and experience to complete their tasks. Supervision is needed to provide more improvement. Step 8, create planning for technicians who have never learned the expected knowledge, skills and attitudes. The TIU formulation will be based on the knowledge, skills, and attitudes required by the technician. TIU consists of 4 parts, namely people who learn, objectives oriented to results (use of the word "will be"), active verbs that can be observed changes, and objects in the form of behavior that's expected to change.

\section{Identify the technician's initial behavior and characteristics.}

Technicians have initial characteristics and behaviors in the form of knowledge, skills and initial attitudes before training begins, characteristics and initial behaviors that affect the ongoing training process that must be analyzed, among others educational background and previous experience that builds the competencies they currently acquire (Adam \& Foster, 2000). This needs to be known in advance to prevent the material that will be learned from being repeated in the new training with the training they have undergone before. Motivation to learn that builds their motivation to learn. This is important to analyze because the motivation of adults to learn is strongly influenced by internal motivation. Access to learning resources relevant to the training material. Ability here means whether they have hardware such as gadgets and laptops to access the internet or materials that will be provided by the training provider.

Their learning habits / styles during face-to-face meetings and when studying independently. This will affect the learning strategy in the training development process. The place of residence or domicile of the technician. The farther they domicile from the training center will affect the training process because they will start training with a tired physical and mental condition, especially if the training center is in the city center. Access to communication in training activities that can be used in training activities. This is important considering that the instructor's guide will determine the technician's understanding of the material. Discipline in setting time to study regularly. It is very important to know the application of rules when training, the more disciplined the technicians, the higher the training success. Habits of systematic learning. Technicians' habit of systematic learning will lead to their understanding, especially for complex materials (Shatto \& Erwin, 2017; Zhu \& Jesiek, 2017).

\section{Analyzing instructional and technology.}

Instructional analysis is the stage where determining the material and materials to be discussed in the training, combined with the analysis of learning materials, available facilities and infrastructure, makes it easier to formulate learning strategies at the time of design (Kozlov \& Shemshurina, 2018; Smaldino et al., 2011). Instructional analysis process determine the material needed by the technician to 
achieve results according to instructional objectives. Each learning goal must have small goals that can help to achieve the final goal, determine some materials that can guide the technician to understand the instructional objectives. Define a sequence of small predefined goals, determine its competency structure. Can be arranged hierarchically, procedurally, cluster or mixed. Analyze learning materials, facilities and infrastructure that are already available and determine what tools and materials can support the materials (Mistry et al., 2016).

This results of the studies on needs analysis used in instructional development models such as Dick \& Carey, MPI and Borg \& Gall show that there are similarities in the needs analysis section. The difference in the results of this study with existing theories is technology analysis. The stage of analyzing the availability of learning materials, facilities and infrastructure is an analysis carried out before deciding to make learning materials. Meanwhile, several studies that specifically develop a training programs for technicians, such as focusing too much on the training materials so that they forget about some important aspects that must be analyzed such as the characteristics of the technician such as their learning style, where they live and other important aspects that described in step 2 of method in research results (Said et al., 2016; Sofyan et al., 2019; Tafakur et al., 2020; Widjanarko et al., 2016).

The results of this research were also supported by the results of interviews with several instructors where the results of the interviews with 9 instructors showed that $100 \%$ agreed that these aspects of the needs analysis were very helpful for facilitating training design and $77.78 \%$ of instructors argued that analyzing the availability of learning materials as well as supporting facilities for training need to be linked to instructional analysis. This addition is necessary because the amount of material will be easier to formulate and learning strategies will be easier to decide. The instructors also agree that this aspect is very important to pay attention to in advance in order to speed up the time to design training and will be more cost effective.

\section{Conclusion}

This research is limited to training in fast changing companies such as the automotive industry and their locations in Indonesia. The needs analysis can be different for other types of companies so it needs to be reviewed if you are going to use this needs analysis stage to design training for nonautomotive companies. The contribution of the results of this research to the field of educational technology is a method for analyzing training needs specifically for technicians in order to assist other researchers in field of educational technology to develop training for technicians. In designing training for automotive companies, this analysis needs to be carried out in a needs analysis in order to shorten design time and costs.

\section{Acknowledgements}

The author thanks the technicians and training instructors at several Astra branch companies as resource persons who have provided guidance and motivation to the author so that this research can be completed properly.

\section{References}

Adam, E. E., \& Foster, S. T. (2000). Quality improvement approach and performance: multisite analysis within a firm. Journal of Quality Management, 5(2), 143-158. https://doi.org/10.1016/s10848568(01)00018-9

Brown, A. H., \& Green, T. D. (2018). Beyond teaching instructional design models: exploring the design process to advance professional development and expertise. Journal of Computing in Higher Education, 30(1), 176-186. https://doi.org/10.1007/s12528-017-9164-y

Bucklin, B. R., Brown, J., \& Conard, A. L. (2018). Increasing Performance in the Automotive Industry Through Context-based Learning. Performance Improvement, 57(2), 26-32. https://doi.org/10.1002/pfi.21770

Chyung, S. Y. (2008). Foundations of instructional and performance technology. HRD Press, Inc.

Deveci, T. (2017). Andragogical , Pedagogical and Lifelong Learning Orientations of Freshman Engineering Students in a Project-Based Course. Education for Life, 31(1), 69-88. http://journals.iku.edu.tr/yed/index.php/yed/article/view/59

Ferreira, D., MacLean, G., \& Center, G. E. (2018). Andragogy in the 21st century: Applying the assumptions of adult learning online. Language Research Bulletin, 32(1). https://www.academia.edu/download/55974504/LRB_Ferreira_MacLean_2017.pdf

Gonzalez, R. V. D., \& Martins, M. F. (2016). Capability for continuous improvement: Analysis of companies 
from automotive and capital goods industries. TQM Journal, 28(2), 250-274. https://doi.org/10.1108/TQM-07-2014-0059

Henshall, E., Campean, F., \& Rutter, B. (2017). A Systems Approach to the Development of Enhanced Learning for Engineering Systems Design Analysis. Procedia CIRP, 60(1), 530-535. https://doi.org/10.1016/j.procir.2017.01.020

Hrastinski, S. (2019). What Do We Mean by Blended Learning? TechTrends, 63(5), 564-569. https://doi.org/10.1007/s11528-019-00375-5

Kozlov, A. V., \& Shemshurina, S. A. (2018). Fostering creativity in engineering universities: Research activity and curriculum policy. International Journal of Instruction, 11(4), 93-106. https://doi.org/10.12973/iji.2018.1147a

LeBrasseur, R., \& Nasierowski, W. (1991). Training and the application of computer- based technology. The Case of Ontario Manufacturing. Technological Forecasting and Social Change, 40(4), 371-388. https://doi.org/10.1016/0040-1625(91)90014-7

Mistry, R. D., Halkude, S. A., \& Awasekar, D. D. (2016). APIT: Evidences of aligning project based learning with various instructional strategies for enhancing knowledge in automobile engineering. International Conference on Learning and Teaching in Computing and Engineering, 107-114. https://doi.org/10.1109/LaTiCE.2016.15

Moica, S., Gherendi, A., Veres, C., \& Moica, T. (2019). The Integration of the Blended Learning Concept into Employee Training as a Factor in Shifting Mentalities towards the Industry 4.0 Approach. International Conference on Industrial Technology and Management, 236-240. https://doi.org/10.1109/ICITM.2019.8710705

Petruni, A., Giagloglou, E., Douglas, E., Geng, J., Leva, M. C., \& Demichela, M. (2019). Applying Analytic Hierarchy Process (AHP) to choose a human factors technique: Choosing the suitable Human Reliability Analysis technique for the automotive industry. Safety Science, 119(1), 229-239. https://doi.org/10.1016/j.ssci.2017.05.007

Prawiradilaga, D. S., \& Chaeruman, U. A. (2018). Modul Hypercontent Teknologi Kinerja (Performance Technology) (1st ed.). Prenadamedia Group.

Said, I. M., Sutadji, E., \& Sugandi, M. (2016). The scientific approach-based cooperative learning tool for vocational students vocation program of autotronic (automotive electronic) engineering. IOSR Journal of Research \& Method in Education, 6(3), 67-73. https://doi.org/10.9790/73880603046773

Seels, B. B., \& Richey, R. C. (1994). Teknologi Pembelajaran: Definisi dan Kawasannya. Unit Penerbitan Universitas Negeri Jakarta.

Shatto, B., \& Erwin, K. (2017). Teaching Millennials and Generation Z: Bridging the generational divide. Creative Nursing, 23(1), 24-28. https://doi.org/10.1891/1078-4535.23.1.24

Shi, H. (2017). Planning Effective Educational Programs for Adult Learners. World Journal of Education, 7(3), 79. https://doi.org/10.5430/wje.v7n3p79

Smaldino, S. E., Lowther, D. L., \& Russell, J. D. (2011). Instructional Technology \& Media for Learning (9th ed.). Kencana.

Sofyan, H., Us, T., Wakid, M., \& Sulistyo, B. (2019). Developing Micro-Teaching Video As Learning Media in Automotive Teacher Education. Journal of Physics: Conference Series, 1273(1). https://doi.org/10.1088/1742-6596/1273/1/012059

Suparman, M. A. (2014). Desain Instruksional Modern (4th ed.). Erlangga.

Tafakur, Yudantoko, A., \& Sudarwanto. (2020). The development of educational media based on the flipped classroom model on practical lesson in vocational education. Journal of Physics: Conference Series, 1446(1). https://doi.org/10.1088/1742-6596/1446/1/012015

Thomsen, A. S. S., Bach-Holm, D., Kjærbo, H., Højgaard-Olsen, K., Subhi, Y., Saleh, G. M., \& Konge, L. (2017). Operating Room Performance Improves after Proficiency-Based Virtual Reality Cataract Surgery Training. Ophthalmology, 124(4), 524-531. https://doi.org/10.1016/j.ophtha.2016.11.015

Widjanarko, D., Sofyan, H., \& Surjono, H. D. (2016). Improving students' mastery on automotive electrical system using automotive electrical multimedia. Research and Evaluation in Education, 2(1), 71. https://doi.org/10.21831/reid.v2i1.8219

Yahaya, S. (2018). The Key Challenges of Implementing E-Learning in Engineering Training Programs. Journal of the Society of Automotive Engineers Malaysia, 2(3), 324-328. http://www.jsaem.saemalaysia.org.my/index.php/jsaem/article/view/65

Zhu, Q., \& Jesiek, B. K. (2017). A Pragmatic Approach to Ethical Decision-Making in Engineering Practice: Characteristics, Evaluation Criteria, and Implications for Instruction and Assessment. Science and Engineering Ethics, 23(3), 663-679. https://doi.org/10.1007/s11948-016-9826-6 